\title{
Risk factors of deep vein thrombosis of lower (4) extremity in patients undergone gynecological laparoscopic surgery: what should we care
}

Qing Tian ${ }^{1,2}$ and Meng Li $2,3^{*}$

\begin{abstract}
Background: Deep vein thrombosis (DVT) significantly influences the prognosis of patients. It's necessary to analyze the risk factors for postoperative DVT in patients undergone gynecological laparoscopic surgery.

Methods: Patients who underwent gynecological laparoscopic surgery from January 1, 2018 to May 31, 2020 were included. The characteristics and clinical data of DVT and non DVT patients were collected and analyzed. Logistic regression analysis was performed to identify the risk factors of DVT in patients undergone gynecological laparoscopic surgery.
\end{abstract}

Results: A total of 355 patients undergone gynecological laparoscopic surgery were included, the incidence of postoperative DVT was $11.55 \%$. There were significant differences in the age, hypertension, D-dimer, duration of surgery, intraoperative pneumoperitoneum pressure, duration of days in bed between DVT and non-DVT groups (all $p<0.05$ ), and there were no significant difference in the BMI, diabetes, hyperlipidemia, ASA classification and intraoperative blood transfusion between DVT and non-DVT groups (all $p>0.05$ ). Age $>50$ years (OR 4.246, 95\% Cl 1.234-7.114), hypertension (OR 2.219, 95\% Cl 1.153-4.591), D-dimer >0.5 mg/L (OR 3.914, 95\% Cl 1.083-5.229), duration of surgery $\geq 60 \mathrm{~min}(\mathrm{OR} 2.542,95 \% \mathrm{Cl} 1.101-4.723)$, intraoperative pneumoperitoneum pressure $\geq 15 \mathrm{mmHg}$ (OR 3.845, $95 \% \mathrm{Cl} 1.119-5.218$ ), duration of days in bed $>3$ days (OR 1.566, 95\% Cl 1.182-1.994) was the independent risk factors for DVT in patients undergone gynecological laparoscopic surgery (all $p<0.05$ ).

Conclusions: The incidence of postoperative DVT in patients undergone gynecological laparoscopic surgery is high, and those high-risk factors should be targeted to intervene in order to reduce the postoperative DVT.

Keywords: Deep vein thrombosis, Gynecology, Laparoscopic surgery, Prevention, Treatment, Nursing care

\section{Background}

In recent years, with the continuous improvement of surgical technology and the improvement of surgical instruments and equipment, deep vein thrombosis (DVT) of the lower extremities is still one of the common complications after gynecological surgery [1]. The feared

\footnotetext{
*Correspondence: mengli33@tom.com

${ }^{2}$ Key Laboratory of Birth Defects and Related Diseases of Women and Children, Sichuan University, Sichuan Province, No. 20, Section 3, Renmin South Road, Wuhou District, Chengdu, China

Full list of author information is available at the end of the article
}

complication of DVT is pulmonary embolism, which is closely associated with higher mortality and poorer prognosis [2]. Furthermore, DVT produce adverse impact on the limb motor function of patients, thereby influencing the daily activity ability and reducing the quality of life [3]. Therefore, the preventions and treatments of DVT are on the top research agenda of current studies.

Compared with traditional laparotomy, gynecological laparoscopic surgery has less damage to the patient's body, and the stress response is less, the patient loses less blood, and the postoperative recovery is faster [4]. 
However, DVT is a serious complication of laparoscopic surgery, which may be associated with intraoperative pneumoperitoneum pressure and other influencing factors [5]. It's been reported that the risk of DVT after surgery is not lower than that of traditional gynecological surgery [6]. Therefore, it is very necessary to understand the related risk factors of DVT after gynecological laparoscopic surgery, to guide the early prevention and intervention of DVT in clinic, and to reduce the occurrence of DVT after surgery [7]. In this study, we aimed to analyze the relevant clinical data of patients undergone laparoscopic surgery, to explore the related factors of postoperative DVT, thereby providing evidence for clinical preventions and treatments of postoperative DVT in patients with gynecological laparoscopic surgery.

\section{Methods}

\section{Ethical approval}

Our study has been verified and approved by the ethics committee of West China Second University Hospital, Sichuan University (No.20180147), and written informed consents have been obtained from all the included patients. All the methods were performed in accordance with the relevant guidelines and regulations.

\section{Patients}

Patients who underwent gynecological laparoscopic surgery from January 1, 2018 to May 31, 2020 were included as potential participants. The inclusion criteria for patients were: (1) the patients were underwent gynecological laparoscopic surgery for the first time; (2) all patients underwent venous color ultrasound to detect the DVT before and after surgery; (3) patients who did not use contraceptives or other hormonal drugs, or drugs that might affect the body's blood clotting function before surgery; (4) patients were well informed and agreed to participant in this study. The exclusion criteria for patients were: (1) Patients who received traditional gynecological open surgery; (2) Patients taking drugs for anticoagulation before surgery; (3) Patients suffering from diseases with abnormal blood coagulation function, such as hemophilia, leukemia et al.; (4) Patients who were not willing to participate in this study.

\section{Diagnosis of DVT}

The diagnosis of DVT referred to the relevant diagnostic guidelines $[8,9]$. The criteria for the diagnosis of DVT included: (1) Clinical manifestations: postoperative pain, numbness, swelling, and limited mobility of the affected side of the lower limb. (2) Signs: The circumference of the lower limb of the affected side was larger than that of the healthy side. The Homans sign was positive. (3) Auxiliary examination: During the color Doppler ultrasound venous examination of the lower extremities, there was substantial echo in the venous cavity.

\section{DVT prophylaxis}

We routinely utilized the mechanical post-operative DVT prophylaxis for all included patients. We encouraged patients to get out of bed as soon as possible and to massage and observe their lower limbs frequently. All the patients underwent electrical stimulation for total of 3 days with Phcnix 200 massager (Guanger biotechnology, Shanghai, China) to start within $12 \mathrm{~h}$ after surgery. The first stage for the first two postoperative days: frequency 20/40/20, pulse width 370/330/370; Second stage for the third day: frequency: 65/105/65; Pulse width: 420/380/420, 30 min each time. The intensity of stimulation was different according to the tolerance of each patient, and it was set to the maximum intensity that could be tolerated by patients without discomfort.

\section{Data collection}

The general patients' information and related clinical data of each included patient were collected and analyzed, which including: patients' age, body mass index (BMI), concurrent complications (diabetes, hypertension, hyperlipidemia), D-dimer value, American Association of Anesthesiologists (ASA) score, duration of surgery, intraoperative blood transfusion, intraoperative pneumoperitoneum pressure, duration of days in bed (the duration of daily bed stay $\geq 20 \mathrm{~h}$ ). All the data were collected and recorded by two authors independently.

\section{Statistical analysis}

This study used SPSS 21.00 statistical software package for statistical processing. The data was expressed in terms of rate. Firstly, single factor analysis was used, and the chi-square test was used to screen out the potential variables, and then multi-factor unconditional binary classification was used. Logistic regression analysis was performed to determine the odds ratio (OR) value of each risk factor and its $95 \%$ confidence interval (95\% CI), and $p<0.05$ was considered statistically significant.

\section{Results}

\section{Included patients}

A total of 355 patients undergone gynecological laparoscopic surgery were included. Of the 355 included patients, 41 patients were diagnosed as DVT after surgery, the incidence of DVT in patients undergone gynecological laparoscopic surgery was $11.55 \%$. The distribution of types of gynecological laparoscopic surgery was presented in Table 1. 
Table 1 Distribution of types of gynecological laparoscopic surgery

\begin{tabular}{lcrl}
\hline Surgery & Total cases & DVT & Incidence (\%) \\
\hline Gynecological accessory surgery & 190 & 22 & 11.58 \\
Myomectomy & 79 & 9 & 11.39 \\
Laparoscopic total hysterectomy & 68 & 8 & 11.76 \\
$\begin{array}{l}\text { Laparoscopic gynecological } \\
\quad \text { malignant tumor surgery }\end{array}$ & 18 & 2 & 11.11 \\
\begin{tabular}{l} 
Total \\
\hline
\end{tabular} & 355 & 41 & 11.55 \\
\hline
\end{tabular}

Table 2 The characteristics of included patients

\begin{tabular}{|c|c|c|c|c|}
\hline Variables & DVT group $(n=41)$ & Non-DVT group $(n=314)$ & $x^{2}$ & $p$ \\
\hline \multicolumn{5}{|c|}{ Age (years) } \\
\hline$<50$ & $7(17.07 \%)$ & $227(72.29 \%)$ & \multirow[t]{2}{*}{1.209} & \multirow[t]{2}{*}{0.031} \\
\hline$\geq 50$ & 34 (82.93\%) & $87(27.71 \%)$ & & \\
\hline \multicolumn{5}{|c|}{$\mathrm{BMI}\left(\mathrm{kg} / \mathrm{m}^{2}\right)$} \\
\hline$<25$ & $26(63.41 \%)$ & $186(59.24 \%)$ & \multirow[t]{2}{*}{1.144} & \multirow[t]{2}{*}{0.101} \\
\hline$\geq 25$ & 15 (36.59\%) & $128(40.76 \%)$ & & \\
\hline \multicolumn{5}{|c|}{ Diabetes } \\
\hline Yes & $12(29.27 \%)$ & $73(23.25 \%)$ & \multirow[t]{2}{*}{1.118} & \multirow[t]{2}{*}{0.062} \\
\hline No & $29(70.73 \%)$ & $241(76.75 \%)$ & & \\
\hline \multicolumn{5}{|c|}{ Hypertension } \\
\hline Yes & $22(53.65 \%)$ & $62(19.75 \%)$ & \multirow[t]{2}{*}{1.133} & \multirow[t]{2}{*}{0.019} \\
\hline No & 19 (46.35\%) & $252(80.25 \%)$ & & \\
\hline \multicolumn{5}{|c|}{ Hyperlipidemia } \\
\hline Yes & $10(24.39 \%)$ & $62(19.76 \%)$ & \multirow[t]{2}{*}{1.181} & \multirow[t]{2}{*}{0.112} \\
\hline No & 31 (75.61\%) & $246(78.34 \%)$ & & \\
\hline \multicolumn{5}{|c|}{ D-dimer (mg/L) } \\
\hline$<0.5$ & $5(12.20 \%)$ & $211(67.20 \%)$ & \multirow[t]{2}{*}{1.226} & \multirow[t]{2}{*}{0.036} \\
\hline$\geq 0.5$ & $36(87.80 \%)$ & $103(32.80 \%)$ & & \\
\hline \multicolumn{5}{|c|}{ ASA classification } \\
\hline Level I & 20 (48.78\%) & $156(49.68 \%)$ & \multirow[t]{2}{*}{1.140} & \multirow[t]{2}{*}{0.074} \\
\hline Level II & $21(51.22 \%)$ & $158(50.32 \%)$ & & \\
\hline \multicolumn{5}{|c|}{ Duration of surgery (min) } \\
\hline$<60$ & $11(26.83 \%)$ & $181(57.64 \%)$ & \multirow[t]{2}{*}{1.183} & \multirow[t]{2}{*}{0.019} \\
\hline$\geq 60$ & $30(73.17 \%)$ & $133(42.26 \%)$ & & \\
\hline \multicolumn{5}{|c|}{ Intraoperative blood transfusion } \\
\hline Yes & $10(24.39 \%)$ & $35(11.15 \%)$ & \multirow[t]{2}{*}{1.128} & \multirow[t]{2}{*}{0.054} \\
\hline No & $31(75.61 \%)$ & $279(88.85 \%)$ & & \\
\hline \multicolumn{5}{|c|}{ Intraoperative pneumoperitoneum pressure $(\mathrm{mmHg})$} \\
\hline$<15$ & $16(39.02 \%)$ & $202(64.33 \%)$ & \multirow[t]{2}{*}{1.102} & \multirow[t]{2}{*}{0.006} \\
\hline$\geq 15$ & $25(60.98 \%)$ & $112(35.67 \%)$ & & \\
\hline Duration & of days in bed & & & \\
\hline$<3$ & $12(29.27 \%)$ & $226(71.97 \%)$ & 1.177 & 0.031 \\
\hline$\geq 3$ & $29(70.73 \%)$ & $88(28.03 \%)$ & & \\
\hline
\end{tabular}

\section{The characteristics of included patients}

As showed in Table 2, there were significant differences in the age, hypertension, D-dimer, duration of surgery,
Table 3 The variable assignment of multivariate logistic regression

\begin{tabular}{lll}
\hline Factors & Variables & Assignment \\
\hline VTE & $Y$ & Yes $=1, \mathrm{no}=2$ \\
Age & $X_{1}$ & $\geq 50=1,<50=2$ \\
Hypertension & $X_{2}$ & Yes $=1$, No $=2$ \\
D-dimer & $X_{3}$ & $\geq 0.5=1,<0.5=2$ \\
Duration of surgery & $X_{4}$ & $\geq 60=1,<60=2$ \\
Intraoperative pneumoperito- & $X_{5}$ & $\geq 15=1,<15=2$ \\
$\quad$ neum pressure & & $\geq 3=1,<3=2$ \\
Duration of days in bed & $X_{6}$ & \\
\hline
\end{tabular}

Table 4 The results of logistic regression analysis on the risk factors of DVT in patients with gynecological laparoscopic surgery

\begin{tabular}{|c|c|c|c|c|c|}
\hline Variables & $\beta$ & $S \bar{x}$ & OR & $95 \% \mathrm{Cl}$ & $p$ \\
\hline Age $>50$ years & 0.833 & 0.213 & 4.246 & $1.234-7.114$ & 0.012 \\
\hline Hypertension & 0.914 & 0.240 & 2.219 & $1.153-4.591$ & 0.028 \\
\hline D-dimer $>0.5 \mathrm{mg} / \mathrm{L}$ & 0.871 & 0.251 & 3.914 & $1.083-5.229$ & 0.008 \\
\hline Duration of surgery $\geq 60 \mathrm{~min}$ & 0.624 & 0.118 & 2.542 & $1.101-4.723$ & 0.031 \\
\hline $\begin{array}{l}\text { Intraoperative pneu- } \\
\text { moperitoneum pres- } \\
\text { sure } \geq 15 \mathrm{mmHg}\end{array}$ & 0.649 & 0.104 & 3.845 & $1.119-5.218$ & 0.022 \\
\hline $\begin{array}{l}\text { Duration of days in } \\
\text { bed }>3 \text { days }\end{array}$ & 0.213 & 0.124 & 1.566 & $1.182-1.994$ & 0.037 \\
\hline
\end{tabular}

intraoperative pneumoperitoneum pressure, duration of days in bed between DVT and non-DVT groups (all $p<0.05)$, and there were no significant difference in the BMI, diabetes, hyperlipidemia, ASA classification and intraoperative blood transfusion between DVT and non-DVT groups (all $p>0.05$ ).

\section{The risk factors for DVT}

We included age, hypertension, D-dimer, duration of surgery, intraoperative pneumoperitoneum pressure, duration of days in bed for further logistic regression, and the variable assignment of multivariate logistic regression was presented in Table 3. And as indicated in Table 4, Age $>50$ years (OR 4.246, 95\% CI 1.2347.114), hypertension (OR 2.219, 95\% CI 1.153-4.591), D-dimer $>0.5 \mathrm{mg} / \mathrm{L}$ (OR 3.914, 95\% CI 1.083-5.229), duration of surgery $\geq 60 \mathrm{~min}$ (OR 2.542, 95\% CI 1.101-4.723), intraoperative pneumoperitoneum pressure $\geq 15 \mathrm{mmHg}$ (OR 3.845, 95\% CI 1.119-5.218), duration of days in bed $>3$ days (OR 1.566, 95\% CI 1.182-1.994) was the independent risk factors DVT in patients undergone gynecological laparoscopic surgery (all $p<0.05$ ). 


\section{Discussions}

At present, there are large differences in reports on the incidence of DVT after gynecological diseases. The incidence of DVT after gynecological surgery ranges from 11 to $29 \%$ [1, 10]. Sakon et al. [11] have pointed out that DVT occurred after gynecological surgery, the incidence of DVT can be as high as $17.5 \%$. Domestic studies by Huang et al. [12] have shown that the incidence of DVT after gynecological laparoscopic surgery is $7.6 \%$. In addition, several studies $[13,14]$ have shown that patients undergone gynecological laparoscopic surgery have significant increased postoperative blood viscosity, the incidence of DVT is about $8 \%$. The incidence of DVT in this present study is $11.55 \%$. The reasons for the differences in these reports may be that the design standards of various investigations are inconsistent, and the lack of multi-center or large-sample series of studies [15]. Furthermore, the operation techniques and methods of gynecological laparoscopic surgery in each hospital are not consistent [16]. Besides, a considerable number of postoperative DVT patients in clinic have no typical symptoms and signs, which brings certain difficulties to clinical DVT diagnosis [17]. Therefore, the incidence of DVT after gynecological laparoscopic surgery is high, and it is necessary to take preventive and intervention measures as soon as possible to reduce the incidence of DVT. The results our study have found that Age $>50$ years, hypertension, D-dimer $>0.5 \mathrm{mg} / \mathrm{L}$, duration of surgery $\geq 60 \mathrm{~min}$, intraoperative pneumoperitoneum pressure $\geq 15 \mathrm{mmHg}$, duration of days in bed $>3$ days the independent risk factors DVT in patients with gynecological laparoscopic surgery, it's necessary to conduct many counteractive or preventative measures targeted on those factors to reduce the occurrence of DVT.

Many published studies $[18,19]$ have shown that the incidence of first DVT increases exponentially with age. Some studies $[20,21]$ have found that the annual incidence of DVT in children younger than 15 is less than $0.005 \%$, but the annual incidence of DVT in adults over 80 years old increased significantly to $0.5 \%$. The main reasons for the high incidence of DVT in elderly patients may be explained as follows: with the increase of age, the activities of elderly patients reduce accordingly, and the blood flow speed in the veins slows down, resulting in less and slower blood flow in the veins of the lower limbs $[22,23]$. Besides, older women often have hypertension, hyperlipidemia, diabetes, etc. These complications can increase the blood viscosity [24]. In addition, with the increase of age, the elasticity of blood vessel walls in elderly patients decreases and the vascular endothelium is easily destroyed [25]. When endothelial cells release more procoagulant substances, the risk of DVT will increase accordingly [26]. Hypertension is a risk factor for DVT. Most patients with hypertension have dysfunction of the renin-angiotensin-aldosterone system, water and sodium retention are increased with more interstitial fluid and decreased plasma content in blood vessels, resulting in increased blood viscosity [27]. The function of vascular endothelial cells in patients with hypertension is disordered, resulting in the production of more oxygen free substance, inactivating more vasodilators, forming vascular inflammation, activating the blood coagulation system, and promoting the occurrence of DVT [28].

Increased D-dimer level is currently considered to be an effective indicator of abnormal blood coagulation system. There are reports $[29,30]$ showing that elevated D-dimer is of great significance in identifying lower extremity arterial thrombosis in peripheral diseases. Studies [31, 32] have reported D-dimer for the prediction of the occurrence of DVT in elderly hospitalized patients, the critical value $\geq 0.5 \mathrm{mg} / \mathrm{L}$ has good predictive value, with a sensitivity of $100 \%$ and a specificity of 41. $8 \%$. The pneumoperitoneum pressure in gynecological laparoscopic surgery is generally about $12-15 \mathrm{mmHg}$, while the normal value of the human inferior vena cava pressure is $2-5 \mathrm{mmHg}$ [33]. The greater the pneumoperitoneum pressure, the greater the pressure on the inferior vena cava, causing slow blood flow [34]. Once the blood becomes a hypercoagulable state, it can also cause endothelial damage and induce platelet activation adhesion and release, increasing the risk of VDT [35].

115 patients in our study had been bedridden for $>3$ days. Although we encourage patients to get out of bed as soon as possible after surgery, most patients still choose to stay in bed. The reason may be related to the patient's fear of pain. We have not use analgesics on the patient after the operation. At the same time, many patients worry that getting out of bed too early will increase wound tension and delay wound healing. When the patient is bedridden for a long time, and the blood flow is slow, thereby the probability of VDT in elderly patients increases significantly. Patients who get out of bed early after surgery can increase muscle contraction, increase blood flow in the lower limbs, and reduce the occurrence of DVT [36, 37].

Pharmacological DVT prophylaxis not considered in our study because our pharmacological DVT prophylaxis is not a routine practice in our department. However, pharmacological DVT prophylaxis is a important issue that merits discreet consideration. The treatment of venous thrombosis mainly includes anticoagulant drugs such as low-dose heparin, low-molecular-weight dextran, and warfarin sodium. Low-dose heparin has little effect on the fetus during pregnancy, but it may cause thrombocytopenia, bleeding and osteoporosis in the body [38]. 
Low-molecular-weight dextran is usually used before and during surgery, but for patients over 40 years old, its effect in preventing postoperative venous thrombosis is not obvious [39]. As the vitamin $\mathrm{K}$ antagonist, warfarin sodium has been widely used in the anticoagulation treatment of various diseases. It can also be used in the treatment of patients with thrombosis or pulmonary embolism after gynecological surgery, but the use of warfarin sodium at any stage of pregnancy may lead to the abnormal development of the central nervous system of the fetus and neonatal bleeding, so warfarin sodium should be avoided as much as possible during pregnancy [40]. The blood coagulation function must be tested during the period of oral anticoagulant drugs [41]. Still the types and doses of pharmacological DVT prophylaxis need further investigations in the future studies.

It is necessary to take active measures to prevent the occurrence of DVT after gynecological surgery. A large number of studies $[42,43]$ have shown that the use of drug preventive measures can reduce the incidence of venous thromboembolism by $40 \%$ to $60 \%$. At present, clinical recommendations for patients should be based on the risk factors for venous thromboembolism, it's possible to give preventive treatment with low molecular weight heparin, unfractionated heparin or fondaparinux [44]. For patients with potential bleeding risk or severe bleeding, mechanical prevention, gradient compression stockings or intermittent inflation compression can be given [45]. Clinically, attention should be paid to the risk of DVT in elderly patients, shorten the operation time and postoperative bedridden time, and special attentions are highlighted to the activities of limb function. It is worth noting that the sample size of cases selected in this study is small and our study is a single-center study. The results of the study should be treated with caution. Future studies with larger samples and multi-centers need to further explore the risk factors of DVT in patients with gynecological laparoscopic surgery, to provide reliable evidence to the prophylaxis of DVT.

\section{Conclusions}

In conclusion, for gynecological laparoscopic surgery patients with age $>50$ years, hypertension, D-dimer $>0.5 \mathrm{mg} / \mathrm{L}$, duration of surgery $\geq 60 \mathrm{~min}$, intraoperative pneumoperitoneum pressure $\geq 15 \mathrm{mmHg}$, duration of days in bed $>3$ days, the risk of DVT is higher, the management of such high-risk factors should be strengthened in clinical practice to reduce the incidence of DVT.

\section{Abbreviations}

DVT: Deep vein thrombosis; BMI: Body mass index; ASA: American Association of Anesthesiologists; OR: Odds ratio; 95\% Cl: 95\% confidence interval.

\section{Acknowledgements}

None.

\section{Authors' contributions}

ML designed research; QT, ML conducted research; QT analyzed data; QT and $M L$ wrote the first draft of manuscript; ML had primary responsibility for final content. All authors read and approved the final manuscript.

\section{Funding \\ None.}

Availability of data and materials

All data generated or analyzed during this study are included in this published article.

\section{Declarations}

\section{Ethics approval and consent to participate}

Our study has been verified and approved by the ethics committee of West China Second University Hospital, Sichuan University (No.20180147), and written informed consents have been obtained from all the included patients. All the methods were performed in accordance with the relevant guidelines and regulations.

\section{Consent for publication}

Not applicable.

\section{Competing interests}

The authors declare that they have no competing interests.

\section{Author details \\ ${ }^{1}$ Department of Operating Room, West China Second University Hospi- tal, Sichuan University, Chengdu, China. ${ }^{2}$ Key Laboratory of Birth Defects and Related Diseases of Women and Children, Sichuan University, Sichuan Province, No. 20, Section 3, Renmin South Road, Wuhou District, Chengdu, China. ${ }^{3}$ Department of Gynaecology, West China Second University Hospital, Sichuan University, Chengdu, China.}

Received: 28 January 2021 Accepted: 10 March 2021

Published online: 26 March 2021

\section{References}

1. Ore AS, Shear MA, Liu FW, Dalrymple JL, Awtrey CS, Garrett L, Stack-Dunnbier H, Hacker MR, Esselen KM. Adoption of enhanced recovery after laparotomy in gynecologic oncology. Int J Gynecol Cancer. 2020;30(1):122-7.

2. Gutzeit O, Lauterbach R, Loberman Z, Sachner R, Karram T, Lowenstein L. Laparoscopic sacrocolpopexy complication: Ilio-femoral deep vein thrombosis. Eur J Obstet Gynecol Reprod Biol. 2020;247:270-1.

3. Moragon-Ledesma S, Galeano-Valle F, Calleja-Carton E, Del-Toro-Cervera J, Demelo-Rodriguez P. Bilateral deep vein thrombosis, vena cava agenesis, and renal abnormalities: KILT syndrome-a case report and literature review. J Cardiovasc Transl Res. 2020;13(4):629-31.

4. Vedantham S. Using it wisely: catheter-directed thrombolysis for deep vein thrombosis. Lancet Haematol. 2020;7(1):e6-7.

5. Yu R, Nansubuga F, Yang J, Ding W, Li K, Weng D, Wu P, Chen G, Ma D, Wei J. Efficiency and safety evaluation of prophylaxes for venous thrombosis after gynecological surgery. Medicine (Baltimore). 2020;99(25):e20928.

6. Chong W, Bui AH, Menhaji K. Incidence and risk factors for venous thromboembolism events after different routes of pelvic organ prolapse repairs. Am J Obstet Gynecol. 2020;223(2):268 e261-268 e226.

7. Carr CE, Chambers L, Jernigan AM, Freeman L, Escobar PF, Michener CM. Short- and long-term outcomes for single-port risk-reducing salpingooophorectomy with and without hysterectomy for women at risk for gynecologic cancer. Int J Gynecol Cancer. 2021;31(2):215-21.

8. Bernardi E, Camporese G. Diagnosis of deep-vein thrombosis. Thromb Res. 2018;163:201-6. 
9. Maufus M, Elias A, Barrellier MT, Pernod G. French Society for Vascular M: diagnosis of deep vein thrombosis recurrence: ultrasound criteria. Thromb Res. 2018;161:78-83.

10. Ackroyd SA, Hernandez E, Roberts ME, Chu C, Rubin S, Mantia-Smaldone G, Houck K. Postoperative complications of epidural analgesia at hysterectomy for gynecologic malignancies: an analysis of the National Surgical Quality Improvement Program. Int J Gynecol Cancer. 2020;30(8):1203-9.

11. Sakon M, Maehara Y, Yoshikawa H, Akaza H. Incidence of venous thromboembolism following major abdominal surgery: a multi-center, prospective epidemiological study in Japan. J Thromb Haemost. 2006:4(3):581-6.

12. Huang H. Analysis of related factors of deep vein thrombosis of lower extremities after gynecological laparoscopic surgery. Clin Med Res. 2015;32(1):146-8.

13. Guo K, Xue H. Diagnosis and treatment of deep vein thrombosis of lower extremities after obstetrics and gynecology. Chin J Pract Gynecol Obstet. 2009;25(5):333-5.

14. Santoso JT, Evans L, Lambrecht L, Wan J. Deep venous thrombosis in gynecological oncology: incidence and clinical symptoms study. Eur J Obstet Gynecol Reprod Biol. 2009:144(2):173-6.

15. Whitworth JM, Schneider KE, Frederick PJ, Finan MA, Reed E, Fauci JM, Straughn JM Jr, Rocconi RP. Double prophylaxis for deep venous thrombosis in patients with gynecologic oncology who are undergoing laparotomy: does preoperative anticoagulation matter? Int J Gynecol Cancer. 2011;21(6):1131-4.

16. Martino MA, Williamson E, Rajaram L, Lancaster JM, Hoffman MS, Maxwell $\mathrm{GL}$, Clarke-Pearson DL. Defining practice patterns in gynecologic oncology to prevent pulmonary embolism and deep venous thrombosis. Gynecol Oncol. 2007;106(3):439-45.

17. Ramirez PT, Nick AM, Frumovitz M, Schmeler KM. Venous thromboembolic events in minimally invasive gynecologic surgery. J Minim Invasive Gynecol. 2013;20(6):766-9.

18. Schmeler KM, Wilson GL, Cain K, Munsell MF, Ramirez PT, Soliman PT, Nick AM, Frumovitz M, Coleman RL, Kroll MH, et al. Venous thromboembolism (VTE) rates following the implementation of extended duration prophylaxis for patients undergoing surgery for gynecologic malignancies. Gynecol Oncol. 2013;128(2):204-8.

19. Suzuki N, Yoshioka N, Ohara T, Yokomichi N, Nako T, Yahagi N, Igarashi S, Kobayashi Y, Yoshimatsu M, Takizawa K, et al. Risk factors for perioperative venous thromboembolism: a retrospective study in Japanese women with gynecologic diseases. Thromb J. 2010;8:17.

20. Yang T, Tian S, Wang Y, Zhao J, Pei M, Zhao M, Wang L, Guo Y, Yang X Evaluation of risk factors for venous thromboembolism in patients who underwent gynecological surgery and validation of a fast-rating assessment table. Med Sci Monit. 2019;25:8814-9.

21. Shi J, Ye J, Zhuang X, Cheng X, Fu R, Zhao A. Application value of Caprin risk assessment model and elevated tumor-specific D-dimer level in predicting postoperative venous thromboembolism for patients undergoing surgery of gynecologic malignancies. J Obstet Gynaecol Res. 2019;45(3):657-64.

22. Pannucci CJ, Fleming Kl. Comparison of face-to-face interaction and the electronic medical record for venous thromboembolism risk stratification using the 2005 Caprini score. J Vasc Surg Venous Lymphat Disord. 2018;6(3):304-11.

23. Cui S, Li H, Tian B, Song C, Hu B. Risk factors associated with venous thromboembolism after lung cancer surgery: a single-center study. Zhongguo Fei Ai Za Zhi. 2018;21(10):753-60.

24. Ma SG, Hu J, Huang Y. The risk factors for perioperative venous thromboembolism in patients with gynecological malignancies: a meta-analysis. Thromb Res. 2020;196:325-34.

25. Rezvani M, Sucandy I, Das R, Naglak MC, Bonanni FB, Antanavicius G. Venous thromboembolism after laparoscopic biliopancreatic diversion with duodenal switch: analysis of 362 patients. Surg Obes Relat Dis. 2014;10(3):469-73.

26. Halawani HM, Ripley-Hager CF, Naglak MC, Bonanni F, Antanavicius G. Venous thromboembolism after laparoscopic or robotic biliopancreatic diversion with duodenal switch: Ninety-days outcome of a 10 years experience. Surg Obes Relat Dis. 2017;13(12):1984-9.
27. Barber EL, Clarke-Pearson DL. The limited utility of currently available venous thromboembolism risk assessment tools in gynecological oncology patients. Am J Obstet Gynecol. 2016;215(4):445 e441-449.

28. Laws A, Anderson K, Hu J, McLean K, Novak L, Dominici LS, Nakhlis F, Carty $M$, Caterson S, Chun Y, et al. Implementation of a venous thromboembolism prophylaxis protocol using the Caprini risk assessment model in patients undergoing mastectomy. Ann Surg Oncol. 2018;25(12):3548-55.

29. Komatsu H, Shimada M, Osaku D, Deura I, Sato S, Oishi T, Harada T. Deep vein thrombosis and serum D-dimer after pelvic lymphadenectomy in gynecological cancer. Int J Gynecol Cancer. 2020;30(6):860-4.

30. Li N, Zhang FB, Li BJ, Wang RT. Combination of preoperative D-dimer and platelet distribution width predicts postoperative deep venous thrombosis in patients with cervical carcinoma. Asian Pac J Cancer Prev. 2019;20(4):1025-9.

31. Burgazli KM, Bilgin M, Kavukcu E, Altay MM, Ozkan HT, Coskun U, Akdere $\mathrm{H}$, Ertan AK. Diagnosis and treatment of deep-vein thrombosis and approach to venous thromboembolism in obstetrics and gynecology. J Turk Ger Gynecol Assoc. 2011;12(3):168-75.

32. Kawaguchi R, Furukawa N, Kobayashi H. Cut-off value of D-dimer for prediction of deep venous thrombosis before treatment in ovarian cancer. J Gynecol Oncol. 2012;23(2):98-102.

33. Fu C, Li GY, Liu FY, Lin QH, Fang XL. Effect of carbon dioxide pneumoperitoneum-laparoscopic surgery on tumor seeding and metastases in endometrial cancer. Zhong Nan Da Xue Xue Bao Yi Xue Ban. 2008:33(2):130-7.

34. Liu X, Wang X, Meng X, Wang H, An Z. Effects of patient position on lower extremity venous pressure during different types of hysterectomy. J Obstet Gynaecol Res. 2015;41(1):114-9.

35. Liu C, Han Z, Zhang N, Peng J, Zhu B, Amin B, Du D, Yan W, Zhang D, Gong K. Laparoscopic sleeve gastrectomy affects coagulation system of obese patients. Obes Surg. 2020;30(10):3989-96.

36. Yamasaki K, Hoshino M, Omori K, Igarashi $H$, Tsuruta T, Miyakata $H$ Nemoto Y, Matsuzaki H, Iriuchishima T. Prevalence and risk factors of deep vein thrombosis in patients undergoing lumbar spine surgery. J Orthop Sci. 2017;22(6):1021-5.

37. Nederpelt CJ, Breen KA, El Hechi MW, Krijnen P, Huisman MV, Schipper IB, Kaafarani HMA, Rosenthal MG. Direct oral anticoagulants are a potential alternative to low-molecular-weight heparin for thromboprophylaxis in trauma patients sustaining lower extremity fractures. J Surg Res. 2021;258:324-31.

38. Kruger PC, Eikelboom JW, Douketis JD, Hankey GJ. Deep vein thrombosis: update on diagnosis and management. Med J Aust. 2019;210(11):516-24.

39. Zhifeng J. Progress in the prevention and treatment of deep vein thrombosis after gynecological surgery. Chin New J Clin Med. 2018;11(12):1280-3.

40. Stone J, Hangge P, Albadawi H, Wallace A, Shamoun F, Knuttien MG, Naidu S, Oklu R. Deep vein thrombosis: pathogenesis, diagnosis, and medical management. Cardiovasc Diagn Ther. 2017;7(Suppl 3):S276-84.

41. Chopard R, Albertsen IE, Piazza G. Diagnosis and treatment of lower extremity venous thromboembolism: a review. JAMA. 2020;324(17):1765-76.

42. Stubbs MJ, Mouyis M, Thomas M. Deep vein thrombosis. BMJ. 2018;360:k351.

43. Boddi M, Peris A. Deep vein thrombosis in intensive care. Adv Exp Med Biol. 2017;906:167-81.

44. Duffett L, Kearon C, Rodger M, Carrier M. Treatment of superficial vein thrombosis: a systematic review and meta-analysis. Thromb Haemost. 2019:119(3):479-89.

45. Farge D, Frere C, Connors JM, Ay C, Khorana AA, Munoz A, Brenner B, Kakkar A, Rafii H, Solymoss S, et al. 2019 international clinical practice guidelines for the treatment and prophylaxis of venous thromboembolism in patients with cancer. Lancet Oncol. 2019;20(10):e566-81.

\section{Publisher's Note}

Springer Nature remains neutral with regard to jurisdictional claims in published maps and institutional affiliations. 